\title{
"Orgastic Man": Olhares Diversos e Profecia
}

\author{
Victor Santos da Costa ${ }^{1}$ \\ DOI 10.20396/eha.vil4.3475
}

Talvez um historiador se atente imediatamente a uma data ao se ver diante de uma obra de arte; no entanto, o meu estímulo inicial partindo de um equívoco de contextualização e de um olhar tendencioso em buscar reforço para alguns meus argumentos, não prestou a devida atenção a história daquela imagem, mas o que poderia ser feito dela, seu eco no meu presente. Ao cometer um equívoco básico de metodologia de pesquisa, imprimir a priori em meu objeto de análise impressões subjetivas, foi possível encontrar uma nova via de entendimento que se tornou mais potente na medida que questiona as formas de se olhar para as obras de arte e propiciar outras evocações poéticas.

A partir de uma perspectiva heurística, se assumirmos como possibilidade abstrata extrair a imagem diante de nós de seu contexto de produção, num contato ideal direto entre o ato de ver e a materialidade vista, me questiono a que recorremos ao nos relacionarmos com os objetos do mundo frente a bagagem cultural que cada um carrega. Diante dessa pergunta, o olhar se apresenta, num primeiro momento, como uma possível resistência a uma educação e às contextualizações necessárias para o desenvolvimento de uma pesquisa visual rigorosamente científica; pode-se pensar no ato de olhar como uma ação sobre as superfícies, no qual a força das aparências e das primeiras impressões se destaca. O primeiro impacto diante da fotografia "Orgastic Man", de Peter Hujar, vem desse local imaginário abstrato, além das regras da razão e das categorias de formato, técnica e período encontradas nas etiquetas que acompanham as obras nos arquivos e nas paredes das instituições expográficas.

Didi-Hubermann explora essas complexas relações do visível. O título dado pelo autor ao trabalho que serviu como escopo teórico para pensar a problemática do meu equívoco, por si só, já apresenta uma importante premissa: a relação entre o que vemos e o que nos olha. Ao resgatar da teologia medieval a necessidade de se distinguir conceitualmente imagem e vestígio (traço, ruína), é proposto o objeto visual como um demonstração de perdas, de desaparecimento de objetos ou

1 Mestrando pelo Programa de Pós-graduação em Artes Visuais: Teoria, Crítica e História da Arte pela Universidade Estadual de Campinas (Unicamp) 
corpos; "coisas a ver de longe e tocar de perto, coisas que se quer e não se pode acariciar. Obstáculos, mas também coisas de onde sair e onde reentrar. Ou seja, volumes dotados de vazios"2.

Assim, como no processo de criação artísticas, as fal has e o acaso se incorporam intimamente ao produto final. Partindo desse terreno dos erros metodológicos, a fotografia de Hujar, de 1969, me olha no presente como uma profecia na medida em que pude encontrar nela diversas características percebidas nas obras dos artistas formados a partir da epidemia de HIV/AIDS dos anos 80 e 90, momento em que o prazer erótico e a ameaça a vida se tornaram praticamente sinônimos. A expressão ambígua no rosto do modelo retratado se torna uma metáfora para essa dicotomia.

O ano da fotografia, 1969, coincide com o ano da Revolta de Stonewall na cidade de Nova York, movimento que foi um dos principais marcos para uma formação política mais ativa da população heterodissidente, o qual daria as bases para a construção das lutas por igualdade sexual nas décadas seguintes. Pertencente a esse contexto histórico-cultural, o conjunto da obra de Peter Hujar expressa, não somente o olhar homoerótico, mas busca retratar os indivíduos de uma cultura homossexual autodefinida e reivindicar um local de identidade política e subjetiva nos contextos da arte canônica.

Nossa cultura não está habituada com representação da figura masculina enquanto objeto de contemplação e desejo, salvo algumas formas iconográficas e contextuais bastante específicas. Na tradição visual do ocidente, esse espaço é majoritariamente ocupado pelo corpo feminino, olhado e representado por homens. Sendo a mulher, dentro da perspectiva heteronormativa e sexista que sustenta o cânone da historiografia da arte, o sexo ideal para ser representada por não se distinguir claramente indivíduo de objeto, ao propor tal deslocamento iconográfico em direção ao corpo masculino, desafiamos nosso olhar a desnaturalizar esses lugares comuns, gerando inúmeras formas de estranhamento. Ao se retratar o homem enquanto objeto sexual, o observador é convertido momentaneamente em um sujeito masculino homossexual. O mesmo não ocorre diante da mulher representada em imagens; estabelecido que o sujeito masculino é o olhar desejante e o produtor natural das representações, não se vê no erotismo da mulher conotações de lesbianismo³.

Nas fotografias de Peter Hujar alguns desses deslocamentos são percebidos e apontam para discussões possíveis ao entorno das maneiras que a figura masculina aparece ao longo da história das produções visuais e que tipo de olhar se lança sobre elas. Pensando-se em uma perspectiva da

\footnotetext{
2 DIDI-Hubermann, 1998, pág. 34-5.

3 CRIMP, 2015.
} 


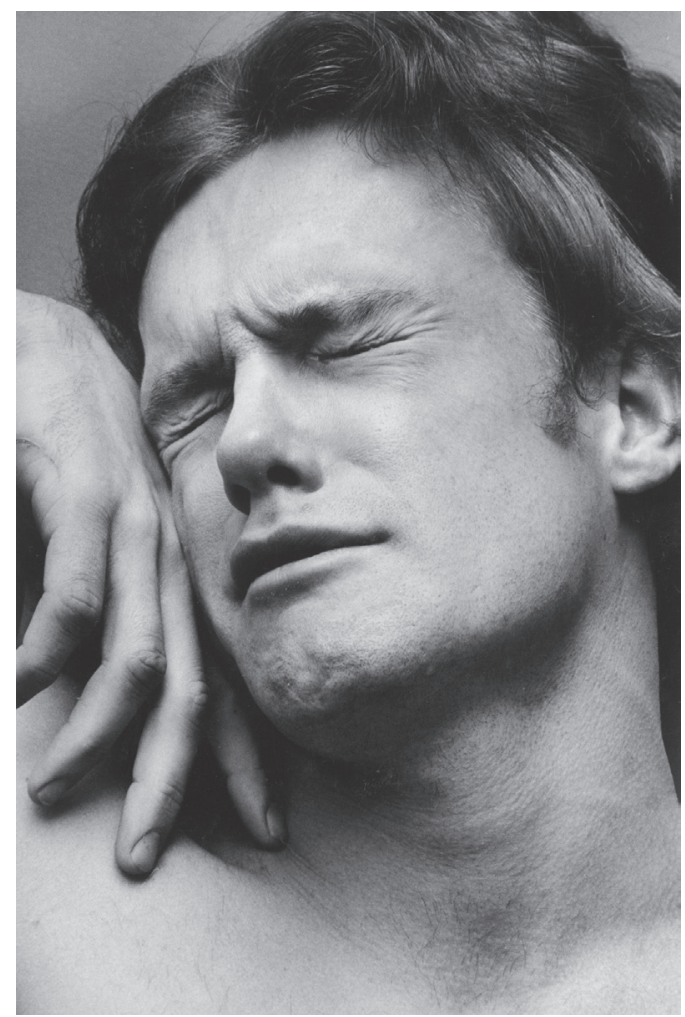

[Figura 1] Peter Hujar. Orgastic Man. 1969

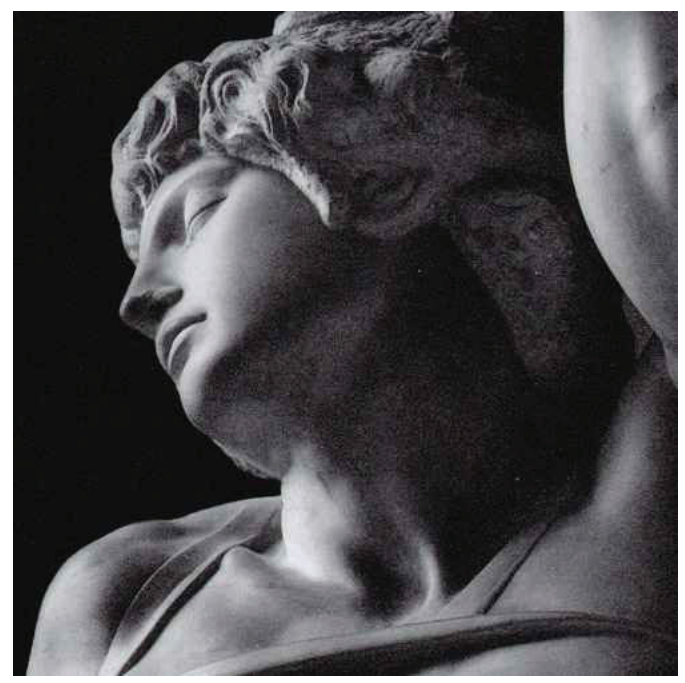

[Figura 3] Michelangelo. Escravo Morrendo (detalhe da obra). 1513

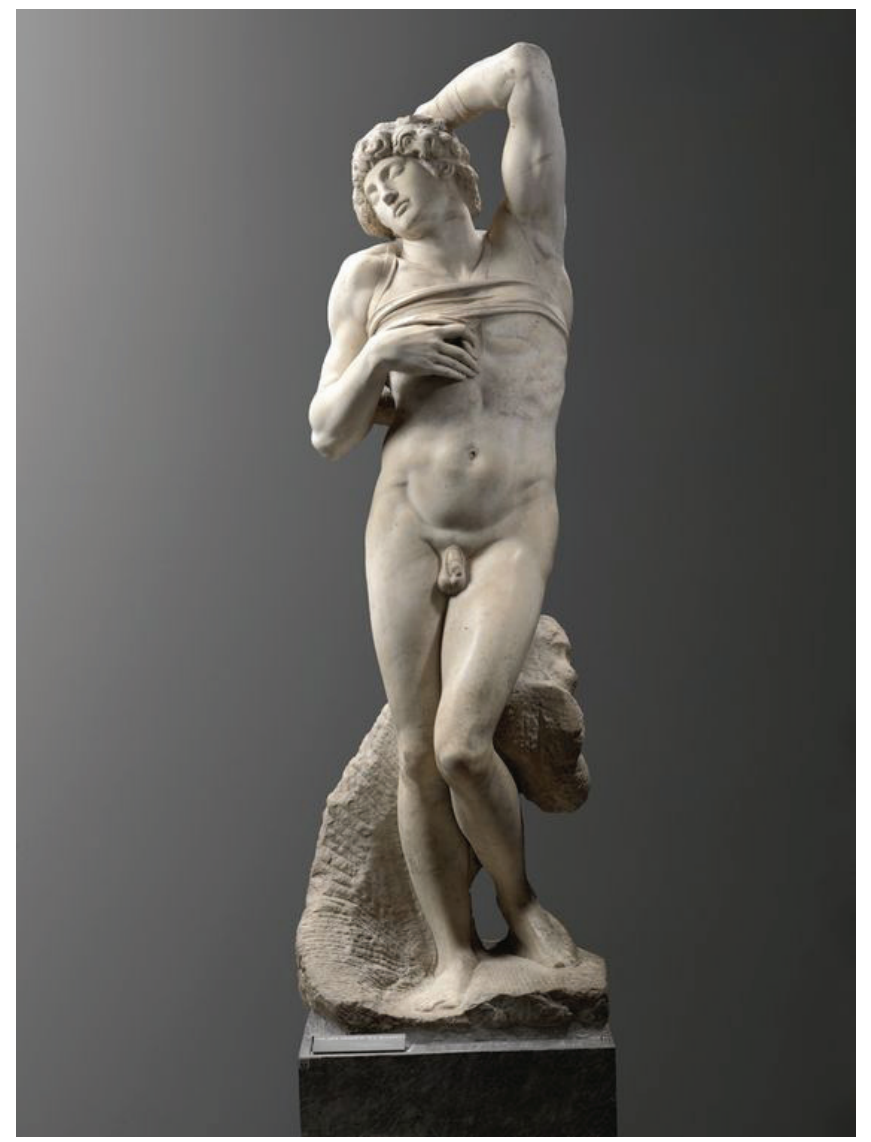

[Figura 2] Michelangelo. Escravo Morrendo. 1513 


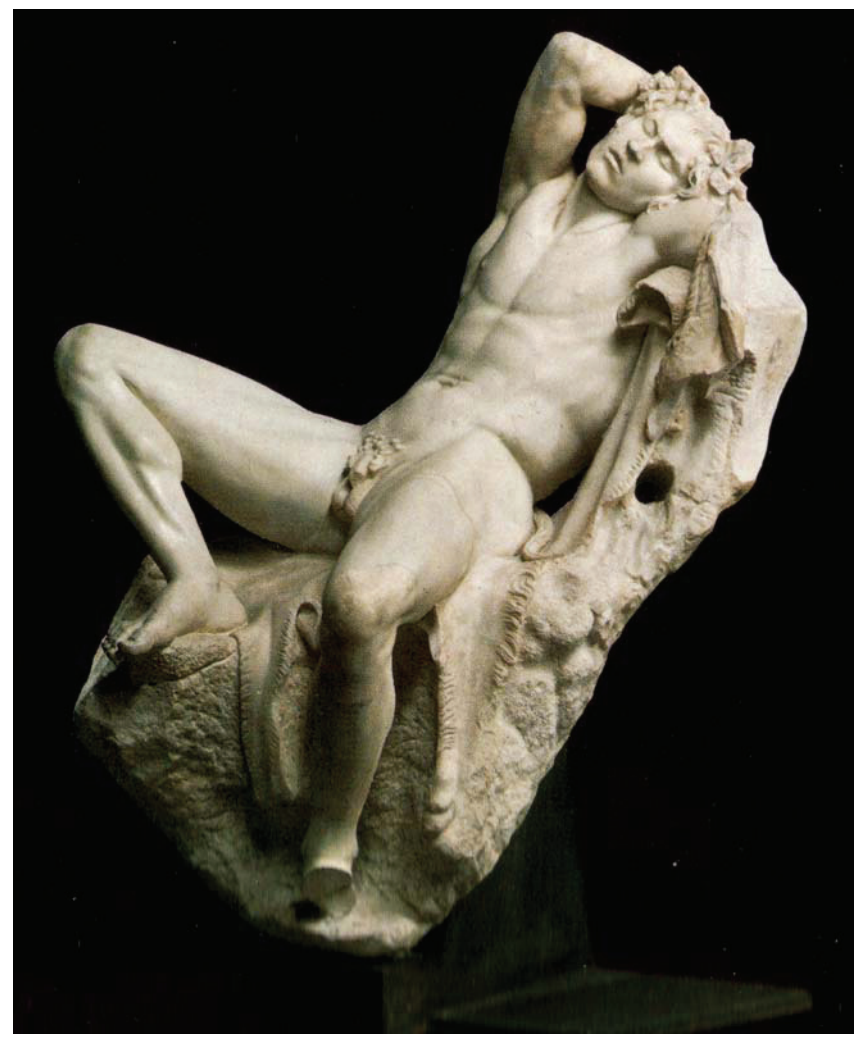

[Figura 5] Autor desconhecido. Fauno Barberini (detalhe da obra). 220 a.C

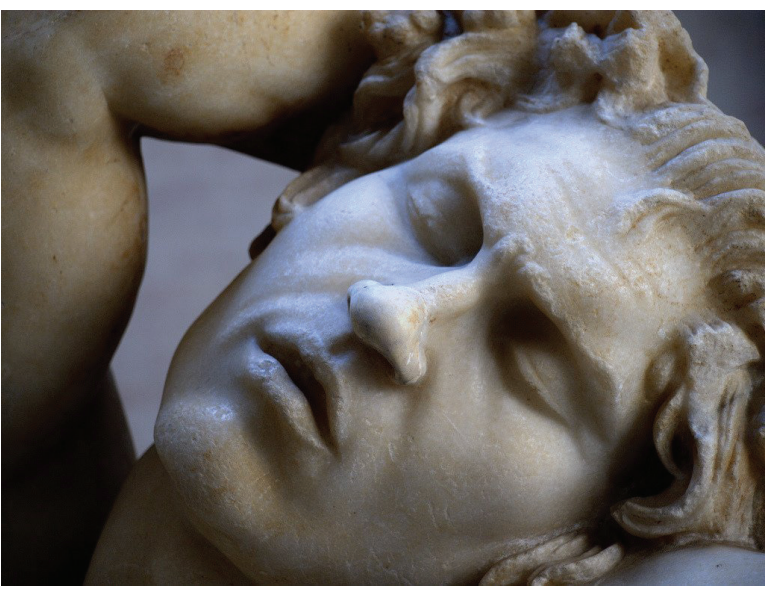

[Figura 4] Autor desconhecido. Fauno Barberini. 220 a.C

[Figura 6]

Nicholas Nixon. Tom Moran, Boston, 1988.

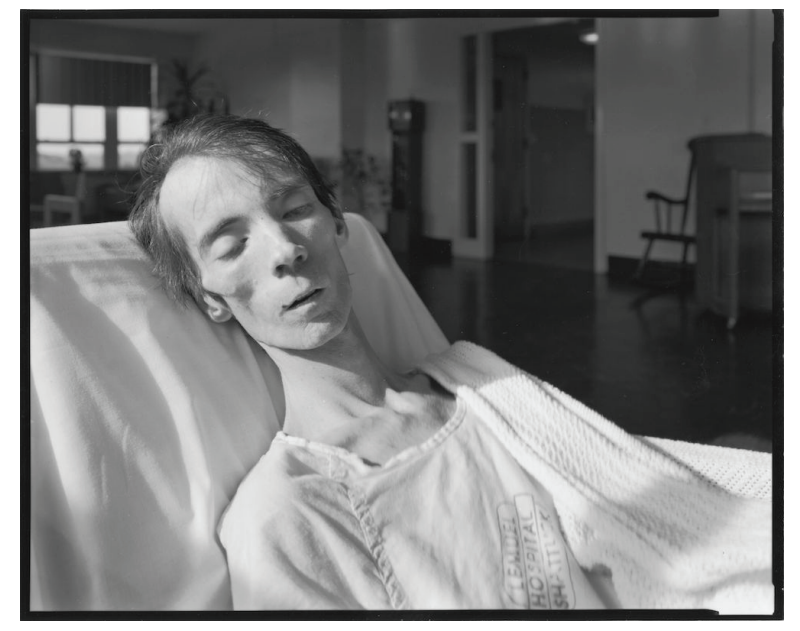

[Figura 7]

David Wojnarowicz. Sem Título

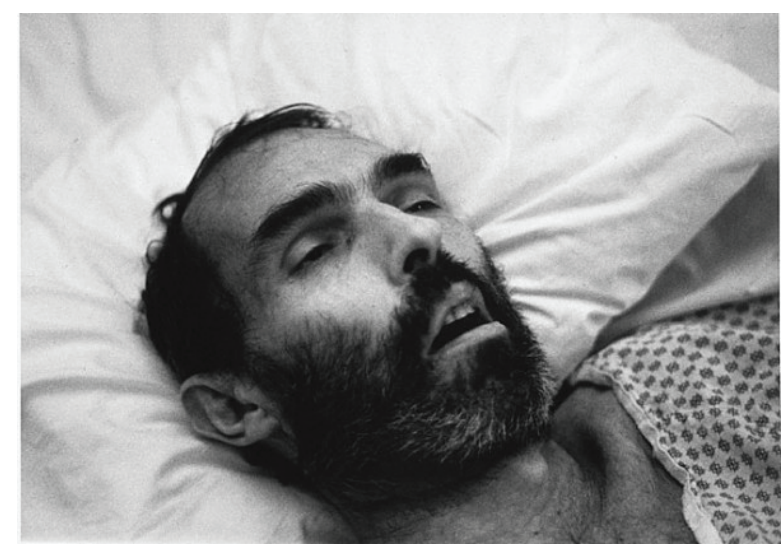

(Peter Hujar). 1989 
iconografias elaborados a partir do sexismo patriarcal e da naturalização da heteronormatividade, chama-se a atenção aqui para alguns elementos recorrentes na abordagem da beleza erótica do homem, assim como para as nuances trazidas pelo olhar do artista atravessado por sua orientação sexual, num período (1969-1979) em que o homoerotismo foi uma questão recorrente na arte ${ }^{4}$

Imagem de caráter bastante ambíguo e desafiadora às formas mais recorrentes de se representar a figura masculina, "Orgastic man" traz a passividade na pose e a intensa carga emocional expressa pelo rosto contorcido do modelo. Desestabiliza-se alguns dos principais pilares da constituição da masculinidade ocidental: o ser ativo e austero, as representações viris e heróicas. Já apresentada por Winkelmann ${ }^{5}$ como parâmetro de qualidade e beleza artística, a austeridade nobre, a recusa à exteriorização das paixões internas são comportamentos esperados tradicionalmente tanto na conduta dos homens quanto em sua representação imagética. No entanto, a fotografia citada cria simultaneamente outras relações que também a aproximam da tradição clássica. Os volumes criados pelo contraste das luzes e sombras bem delineadas sobre a pele clara remete ao mármore das esculturas; a delicadeza harmônica gerada pela relação da mão do modelo repousando ao lado de seu rosto resgata os corpo marmóreos de "Escravo morrendo" de Michelangelo e ao adormecido "Fauno Barberini". O rosto, porém, escapa ao classicismo da pose e se aproxima de uma intensidade quase barroca ao expressar a intensidade de uma fisionomia tomada pelo êxtase ou pelo sofrimento das paixões. Tais ambiguidades convivem numa relação de tensão dentro da fotografia, fortalecida por seu título enquanto chave de leitura: o homem orgástico.

Além de compartilharem a beleza dos corpos masculinos, as três obras citadas têm em comum a apresentação de suas figuras deitadas passivamente, de olhos fechados. Somente ao cerrar o veículo de comunicação visual, é permitido observar, em sua vulnerabilidade, aquele que tradicionalmente detém o papel de observador. Essa construção imagética do corpo adormecido se relaciona ao cadáver. Partindo de um extenso repertório com bases na mitologia clássica de belos jovens rapazes mortos violentamente (Jacinto, Ícaro, Narciso e Antino, por exemplo) ${ }^{6}$, as obras de Michelangelo e Hujar se relacionam mais intimamente nesse aspecto. O orgasmo convulsivo presente no rosto do modelo da fotografia evoca a figura de linguagem francesa la petite mort - a pequena morte. Misto de dor e prazer, a expressão facial ambígua do homem retratado por Hujar faz com que se reflita sobre a dupla natureza do erotismo e do sexo homossexual: proibido, reprimido, incontrolável

\footnotetext{
4 MAHON, 2005.

5 Winckelmann 1975

6 GREER, 2003
} 
desejo transgressor; a inescusabilidade de se desviar da norma e estar sujeito às consequências da homofobia; ao satisfazer-se eroticamente com outro homem vem o gozo e a dor de pecar, de transgredir. Se olhada pela ótica da epidemia de AIDS, que viria a informar a geração dos anos 80 e 90 , a qual dentre tantas vidas também ceifou a de Peter Hujar, a fotografiia evidencia a íntima relação entre o sexo gay e a morte, tornando a expressão la petite mort literal e profética. Aquele que ousa desobedecer a prática do sexo heterossexual, reprodutivo, sustentador da instituição familiar nos moldes patriarcais e capitalistas, ao invés de ser punido com o inferno após a morte das escrituras bíblicas, o suplício de seu inferno, sua agonia, se dá em vida na terra. Definha-se dolorosamente por conta de uma enfermidade que, por pouco se conhecer os sintomas, suas formas de contágio, numa situação de emergência e terror coletivo, agravado pelo descaso das forças publicas da época em combatê-la, assume proporções místicas.

É possível pensar a história da homossexualidade como sendo predominantemente a história da homofobia. No entanto, a partir da segunda metade do século $X X$, outro sinônimo pode ser incorporado à expressão: a história da resistência desses grupos e as perspectivas de lutas políticas puderam competir com as forças socialmente repressivas. No contexto estadunidense, a década de 70 foi marcada por grandes agitações populares em favor da igualdade das minorias oprimidas. Pensando-se em histórias da sexualidade, em especial no caso da história dos homens gays no século XX, é impossível não relacioná-la ao trauma sofrido pela comunidade com a epidemia de HIV/ AIDS iniciada nos anos 80 e aos retrocessos políticos gerados a partir da disseminação da doença. Mesmo não sendo o único grupo amplamente afetado, a epidemia foi culturalmente construída como sinônimo da homossexualidade masculina. Durante esse período, a homofobia alcançaram outras dimensões, afetando não apenas as políticas de saúde pública, como também foram empreendidas perseguições e censuras no âmbito artístico, sendo a restrospectiva "The Perfect Moment" de Robert Mapplethorpe o exemplo mais emblemático desse período. As estratégias de instigar o pânico moral como ferramenta de restabelecer a heteronormatividade por meio do medo ao corpo e a sexualidade foi amplamente empregada. Na arte se observa tal fenômeno, por exemplo, em projetos de leis que proibiam investimentos públicos para artistas cujo trabalho remetia a práticas sexuais dissidentes (considerados obscenos) e na disseminação de imagens que enfatizam o caráter fóbico dos portadores do vírus. A série fotográfica de Nicholas Nixon "People with AIDS", formando parte da retrospectiva do artista realizada pelo MoMA em 1988, opera nesse sentido ao retratar 
a decadência física e a morte dos pacientes portadores de HIV7. Não obstante, termos como "peste gay" e "câncer gay", vindos do vocabulário médico (secular), são empregados amplamente tanto na mídia quanto por importantes figuras políticas, ao mesmo tempo que a AIDS é colocada como punição divina (religioso) em resposta a revolta contra os padrões sexuais heteronormativos. Após a retirada da homossexualidade da lista de doenças psiquiátricas dos Estados Unidos em 1973, enfraquece-se a potência do discurso médico e jurídico como meio de racionalizar a homofobia; porém com a ampla disseminação do vírus e o agravamento da epidemia, ainda apoiando-se no discurso moral da religião, o discurso homofóbico se atualiza. Organizando uma narrativa meticulosa e cooptando outra vez a medicina, apoiada na estatística, foi possível criar justificativas plausíveis para a homofobia junto ao racionalismo científico exigido por uma sociedade moderna, as quais se estendem para além do argumento religioso. Nota-se, dessa forma, um argumento implícito para a eliminação dos sujeitos mais afetados pela epidemia de HIV/AIDS, grupos indesejáveis para o projeto social estadunidense da época: a população negra, latina e os homens gays, operando como uma limpeza social

Roland Barthes em "A Câmara Clara" afirma que a fotografia nos coloca imediatamente diante da morte, porque congelamos no tempo o instante que se esvaiu, uma aparência que o tempo transformará, assim o corpo que ali se encontra já se torna um fantasma antes mesmo da morte do sujeito; o espectro da morte nos encara de volta na fotografia, porque a vida é dinâmica e só a morte é a pausa diante da vida ${ }^{8}$. O recurso fotográfico como meio expressivo, a partir da chave de leitura epidêmica, assume uma nuance cruel - não apenas pela suposta crueza que atribuem ao gênero como fragmento da realidade, mas de crueldade gerada pela especificidade de seu suporte que grava em sua superfície a memória de um corpo refletindo luz; neste caso,do corpo do modelo, jovem, erotizado pela composição do artista, em um momento pré-epidêmico onde se poderia usufruir dos primeiros benefícios do coming out social e da luta pelos direitos iguais da comunidade gay; um momento em que na história da homossexualidade a dimensão da resistência pode se equiparar à dimensão da homofobia em última análise, antes que o espectro da AIDS fosse utilizada como pretexto para o recrudescimento de políticas opressoras.

A abordagem da arte fotográfica proposta por Barthes e as perspectiva das imagens enquanto resquício e vazio de Didi-Hubermann, no contexto que parte de meu equívoco metodológico, 
podem ser aproximadas no caso de "Orgastic man" ao se adaptar o termo "túmulo por "fotografia":

Por um lado, há aquilo que vejo do túmulo, ou seja, a evidência de um volume, em geral, uma massa de pedra, mais ou menos geométrica, mais ou menos figurativa, mais ou menos coberta de inscrições: uma massa de pedra trabalhada seja como for, tirando de sua face o mundo dos objetos talhados ou modelados, o mundo da arte e do artefato em geral Por outro lado, há aquilo, direi novamente, que me olha: e o que me olha em tal situação não tem mais nada de evidente, uma vez que se trata ao contrário de uma espécie de esvaziamento. Um esvaziamento que de modo nenhum concerne mais ao mundo do artefato ou do simulacro, um esvaziamento que, aí diante de mim, diz respeito ao inevitável por excelência, a saber: o destino do corpo semelhante ao meu, esvaziado de sua vida, de sua fala, de seus movimentos, esvaziado de seu poder de levantar os olhos para mim. Eque no entanto me ol ha num certo sentido - o sentido inelutável da perda posta aqui.

Temos a materialidade do registro fotógrafico-túmulo, do olho que se voltou atentamente para o modelo através do anteparo da lente da câmera, eternizando-o como um corpo sadio, erótico, em que a dimensão do orgasmo, da morte ou da dor se encontra virtualmente em sua expressão. Não temos a crueza da realidade que faz definhar a todos os corpos, apenas podemos percebê-la no devir de um orgasmo contínuo, se assim escolhermos olhá-la.

Pela lente da fotografia de Peter Hujar ou pelas lentes da AIDS, em potência, a morte se encontra impregnando toda a imagem. Por essas razões, ao lançar meu ol har para a fotografia ignorando o dado de sua historicidade, fui levado a encontrar ali recursos para construir uma análise que abarca a dimensão epidêmica, mas que também não se esgota nela. Por isso, a chamo de profética e assim me permito alguns recursos para olhar obras de períodos subsequentes, atualizar as interpretações e a vida das obras no mundo, reconhecer alguns códigos e propor novas questões a suas formas e, especialmente, às escolhas estilísticas-iconográficas que compõem essas formas.

9 DIDI-Hubermann, 1998 pág. 37 
Referências Bibliográficas

BARTHES, Roland. A camara clara: nota sobre a fotografia. Coautoria de Julio Castanon Guimarães. Rio de Janeiro, R]: Nova Fronteira, 2000. 185p, il. ISBN 8520904807 (broch.).

CRIMP, Douglas. Melancholia and moralism: essays on AIDS and queer politics. Cambridge [Estados Unidos]: MIT, c2002. 319p., il. ISBN 0262532646 (broch.).

CRIMP, Douglas. Sobre as ruínas do museu. Fotografia de Louise Lawler. Tradução de Fernando Santos. [2. ed.] São Paulo, SP: Martins Fontes, [2015]. 303 p., il. (Coleção A). ISBN 9788580632330 (broch.).

DIDI-HUBERMAN, Georges. O que vemos, o que nos olha. São Paulo, SP: Editora 34, 1998. 260 p., il. (Coleção TRANS). ISBN 8573261137 (broch.).

GREER, Germaine. The boy. Londres: Thames and Hudson, 2003. 256 p., il. ISBN 050023809X (enc.).

MAHON, Alyce. Eroticism \& art. Oxford; New York, NY: Oxford University Press, 2005. 334p., il. ISBN 0192801872 (enc.)

WINCKELMANN, Johann Joachim. Reflexões sobre a arte antiga. Porto Alegre, RS: UFRGS : Movimento, 1975. 70p. (Dialetica, v.3). 